\title{
Electro-Hydraulic Drive of the Variable Ratio Lifting Device under Active Load
}

\author{
Kosucki, A. - Stawiński, Ł. - Morawiec, A. - Goszczak, J. \\ Andrzej Kosucki ${ }^{1}$ - Łukasz Stawiński ${ }^{1}$ - Adrian Morawiec ${ }^{1}$ - Jarosław Goszczak ${ }^{2}$ \\ ${ }^{1}$ Lodz University of Technology, Institute of Machine Tools and Production Engineering, Poland \\ ${ }^{2}$ Lodz University of Technology, Department of Vehicles and Fundamentals of Machine Design, Poland
}

Hydraulic systems fed by fixed displacement pumps driven by frequency-controlled electric motors can replace conventional throttling systems due to their ability to control the speed of hydraulic cylinders regardless of the value and direction of the load. These systems can improve the energy efficiency of the drive or even provide the possibility of energy recuperation during lowering. This paper presents experimental studies of the new drive system with volumetric control of the speed of the lifted/lowered payload using the example of a scissor lift. The system uses a reversible gear pump driven by an asynchronous motor fed by a frequency inverter operating in field-oriented control mode. Comparative studies of the mapping of the assumed speed of the hydraulic cylinder and platform are presented, as well as studies of the influence of the load change on the speed and positioning of the mechanism driven by the open-loop controlled system.

\section{Keywords: hydraulic drives, speed controlled pump, variable-ratio device, lifting system}

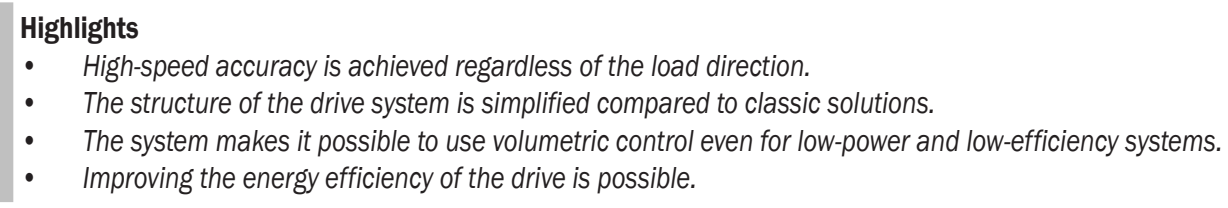

\section{INTRODUCTION}

Hydraulic excavators, elevators, wheel loaders, various forklifts, scissor lifts, and other mobile and stationary machinery use hydraulic lifting systems with hydraulic cylinders to drive the payload with throttling control during payload lowering. The lowering phase is usually caused by gravity. Generally, this requires the use of appropriate valves or complex control systems to protect the load against uncontrolled falling. The most common solution is to use a throttle valve. The typical hydrostatic lifting system, presented in Fig. 1, consists of a hydraulic power supply unit equipped with an oil tank assembly (3), the motor (1), the oil pump (2), and a set of valves, such as the pressure relief valve (4), the directional valve (5), the one-way throttling valve (6) and the rupture valves (7) screwed into the inlets of hydraulic cylinders (8).

The one-way throttling valve during the lowering payload operates as an adjustable choke in which the oil flow rate depends on a pressure drop between the inlet and outlet $\mathrm{D} p_{s}$, according to Eq. (1):

$$
Q_{D}=A_{D} \cdot c_{D} \cdot \sqrt{\frac{2 \Delta p_{s}}{\rho}},
$$

where $A_{D}$ is the cross-sectional area of the valve orifice, $c_{D}$ the coefficient of flow losses, and $\rho$ the density of the hydraulic liquid.
Usually, the throttle valve is set to the defined value of the cross-sectional area of the orifice. When the hydraulic cylinder is loaded with a constant force, this results in a constant pressure under the piston and a constant lowering speed, according to Eq. (2):

$$
v_{s}=\frac{d x_{s}}{d t}=\frac{Q_{D}}{\frac{\pi \cdot d_{s}^{2}}{4}},
$$

where $x_{s}$ is the length of the hydraulic cylinder, and $d_{s}$ the diameter of the hydraulic cylinder.

However, many mechanisms act on hydraulic cylinders with a variable force during their movement, which could be caused by a load change or a variable ratio of driven mechanisms. The changing force acting on the hydraulic cylinder causes the variable pressure under the piston. The higher the pressure, the greater the flow rate through the throttle valve, and thus the increase of the payload lowering speed. It happens when the mechanism ratio changes during the duty cycle (together with the extension/retraction of the hydraulic cylinder). Then the speed of the piston rod changes with the change of mechanism ratio, as shown in Fig. 2.

This type of drive has many disadvantages, such as heating the oil on the throttle valve during the lowering phase, resulting in the need to dissipate the potential energy. It could be then necessary to use oil coolers, which increases the cost of the system. The 
dynamic overloads of the cylinder and mechanism appear caused by a directional valve that is rapidly opened (or closed) by a solenoid, which can lead to premature wear of the machine. The speed of payload lowering using the throttle valve is less controllable.

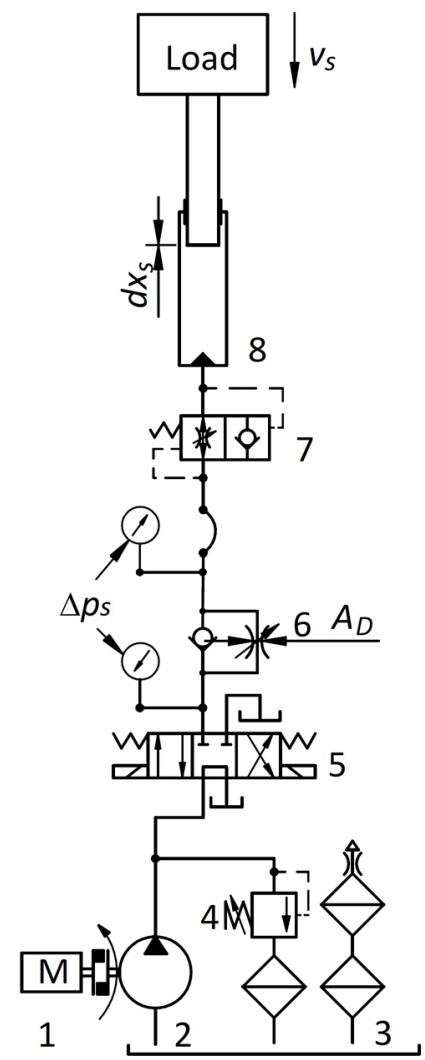

Fig. 1. Schematic of the conventional hydraulic lifting system

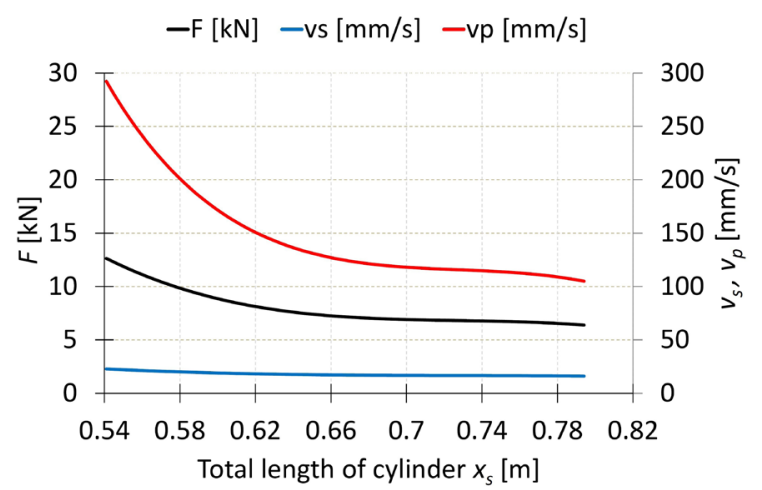

Fig. 2. The exemplary relationship between the speed of the piston rod $v_{s}$, the speed of the platform $v_{p}$, and its load $F$ during lowering

In addition to systems with a throttle valve, other solutions are used in hydraulic systems to control hydraulic cylinders loaded with the active force. The review of the controllability of such systems is described in [1]. These systems use variable displacement pumps, throttle valves, or proportional and servo valves. There are also special braking valves used in hydrostatic systems driving hydraulic cylinders with an active load, called counterbalance valves, described in [2]. In [3], variable hydraulic cylinder load (from passive to active) during one full cycle of motion was discussed. The author dealt with the subject of piston rod braking with the use of, among others, controlled check valves and various types of counterbalance valves. The principle of operation and the benefits of counterbalance valves, which are load holding, load control, and load safety, described in [4]. Incorrect application can lead to negative pressure or stoppage of operation of the device due to insufficient pressure difference. Problems that may occur in systems with counterbalance valves are described in [5]. The use of the right valve depends on the needs, which is why it is so important to know about the capabilities of a given element. A detailed division of counterbalance valves and their advantages and disadvantages are described in [6] and [7].

Counterbalance valves are used to control the movement of the actuator, usually with an active or variable load. Authors in [8] describe an approach that shifts the task of throttling the return flow from the counterbalance valve to the directional valve. The counterbalance valve can also be used to start and stop rotating parts smoothly. The controlled motion of hydraulically actuated transmissions characterized by large inertias, backlash, and several parallel-coupled gearmotors is described in [9]. The analysis of the operation of the counterbalance valves was also tested on the basis of simulation models. The principle of operation of a pressure valve with two control signals is described in [10]. Based on the counterbalance valve model, the author [11] attempted to analyse the influence of the brake valve setting on the valve response. The counterbalance valve operation model with its various settings was verified in the crane's drive system [12]. The use of counterbalance valves can also reduce the energy consumption of the systems. In [13], a closed-circuit system with hydraulic motors and counterbalance valves for supplying an electro-hydraulic actuator is described. The use of such systems yields a $50 \%$ lower energy consumption. The possibilities of reducing pressure peaks and drops, described in [14], lead to a reduction of energy consumption by up to $80 \%$. The use of a counterbalance valve in a variable load system in a truck crane [15] reduces the oscillation by up to $40 \%$, which increases the efficiency and extends the service life of the machine. During the operation of such 
systems, the problem may be the need to generate additional pressure for pump operation and oil heating because of the friction caused by flowing through these valves. In addition, the settings of such valves must be adapted to the acting forces.

The solution that eliminates the problem of load change is the load-sensing system. A comparative study of scissor lift drives carried out based on digital simulation technology of the quantitative pump hydraulic system and the load-sensing hydraulic system is presented in [16]. The author found that the load-sensing hydraulic system is more energy-saving, stable, and prevents interference than the conventional one. However, the system is sensitive to setting the pressure difference on the valve, which was set after the batch analysis. Moreover, it is still an expensive solution.

A volumetric control can be used to control the speed of the hydraulic cylinder. A variable displacement pump can be used, but preferably in systems with higher power $\left(8 \mathrm{~cm}^{3} / \mathrm{rev}\right)$. Another method is to use a device that changes the speed of the motor driving the fixed displacement pump, called a variable speed pump drive (VSPD). The problem of maintaining the assumed speed of the motor is solved in electric drives by using a frequency inverter (FI), which are increasingly used in hydraulic systems instead of complex and expensive systems with variable volume pumps.

The implementation of electronics to hydraulic systems gives a much greater possibility of controlling the movement of actuators and increases energy benefits in relation to typical valve solutions. Positioning control methods can be based on digital pump-motor technology with multiple independent outlets connected directly to the cylinder chambers, which eliminates the need for valves and the generation of energy losses. Described in [17], the digital hydraulic power management system (DHPMS) is a solution that significantly improves the energy efficiency of hydraulic systems [17]. Another example to achieve the double goals of high precise tracking performance and high energy efficiency, a completely new hardware configuration that connects a direct driven pump and independent metering valves is proposed in [18]. The combination of a pump efficiency control system in the form of a variable speed drive motor and a proportional valve set offers energy advantages over conventional valve systems. Both systems operate only in an open-loop controlled based on the position tracking of the hydraulic cylinder.
In [19], an experimental forklift drive with the possibility of energy recovery is presented. However, this is not a very popular method of controlling the speed of a hydraulic cylinder. Three different ways of control, the pressure of the hydrostatic drive using variable displacement pump and FI were presented in [20]. The authors in [21] presented the possibility of controlling the output flow of a hydraulic pump driven by a motor with FI. In [22], the authors described the use of FI in several hydrostatic systems, including the drive of hydraulic cylinders. These systems operate based on direction pumps in the following configurations: variable displacement pumps cooperating with a motor supplied by the power network or a fixed displacement pump with a motor fed by FI. Performances for the same three systems in [23] have been discussed, more specifically including efficient displacement.

An interesting combination of methods of controlling the speed of an actuator loaded with variable force is the research on a self-contained electro-hydraulic cylinder (SCC) presented in [24]. The system, in the author's opinion, has the potential to replace both conventional hydraulic systems and electro-mechanical counterparts, enhancing energy efficiency and reducing maintenance. The system combines an electric servomotor and a fixed displacement pump, the single rod double-acting cylinder, and a low-pressure accumulator arranged in a closed-circuit configuration. The issue of energy recovery in hydrostatic systems with double-acting cylinders also appears in [25]. The double-pump system, with its displacement balanced with the piston area ratio, is used.

Most of the available literature deals with a double-acting cylinder, where the control possibilities are wider than in the case of a plunger cylinder (single-acting), which is presented in this article.

The use of the FI in typical drive systems with directional flow valves is the simplest and relatively inexpensive solution. In [26], the research of the use of FI together with a simple flow directional valve to control the scissor lift operation was presented. The authors described the possibility of lifting the system with a variable ratio, with different loads, maintaining a constant speed of the working platform. Based on the platform position sensor and known machine geometry, the FI control function was calculated. The generated input functions proportional to the assumed speed with proper acceleration and deceleration times allowed reducing the vibration of the hydraulic cylinder, the entire machine structure, 
and the transported payload. However, lowering the payload using a scissor lift is a more complex matter and requires additional assumptions, which have not yet been presented in the publications. Additionally, the usage of the proposed system can also improve the energy efficiency, as presented in [27].

The proposed new simple electro-hydraulic system with a fixed displacement pump driven by an electric motor fed by FI in field-oriented mode and a simple controller fulfill the main goals of this control system, which are:

- ability to shape the speed of the hydraulic cylinder (or any actuator) freely, both during lifting and lowering;

- maintaining the assumed speed of the hydraulic cylinder (or any actuator) independently from the value and direction of the load.

The authors developed a simple hydraulic system, which, using the FI properties, allows full control of the speed of the cylinder or the lift platform when lowering (or lifting) the payload. It is a complete change of the control method compared to the most commonly used solutions, specifically, throttling control with volumetric control. A new control method can also reduce the oil temperature raising effect existing in drives with throttle control. The drive was installed on a real scissor lift.

This paper aims to introduce the experimentally confirmed system that achieves the assumed speed mapping of the plunger cylinder regardless of the load during the lowering cycle (active load) of the variableratio mechanism. The proposed drive can be used either with high or low nominal power installed. The case of active load (e.g., during the lowering phase) in hydraulic systems is difficult to control using the throttle control method (speed depends on the load), and the systems with variable displacement pumps or proportional valves used are expensive.

The paper is organized as follows: Chapter 1 presents the problem statement. Chapter 2 describes the presented solution. The test stand and its main parameters are presented in Chapter 3. The results of the experimental tests are shown in Chapter 4. Conclusions are drawn in Chapter 5.

\section{PROBLEM STATEMENT}

There are many examples of drives when the force on the hydraulic cylinder changes during machine operation due to the kinematic connections of subsequent structural members of the machine. As an example of such a stationary machine, a scissor lift was considered (Fig. 3). It is a mechanical handling device designed for lifting people or payloads to a defined height. Different designs of the driving system of scissor lifts are presented in [28]. A complex geometry results in a variable ratio $i$, which causes a change in a platform speed at a constant speed of the hydraulic cylinder. The variable ratio also entails a variable force on the drive unit as a function of the lifting height (or cylinder stroke), resulting from the weight of the structure and the payload being carried. The problem of the optimal design of the construction and reducing the force acting on the hydraulic cylinders is presented in [29] and [30]. The design of a scissor lift aims at obtaining the smallest mechanism ratio changes, meaning small changes of the working platform speed concerning the speed of the hydraulic cylinder.

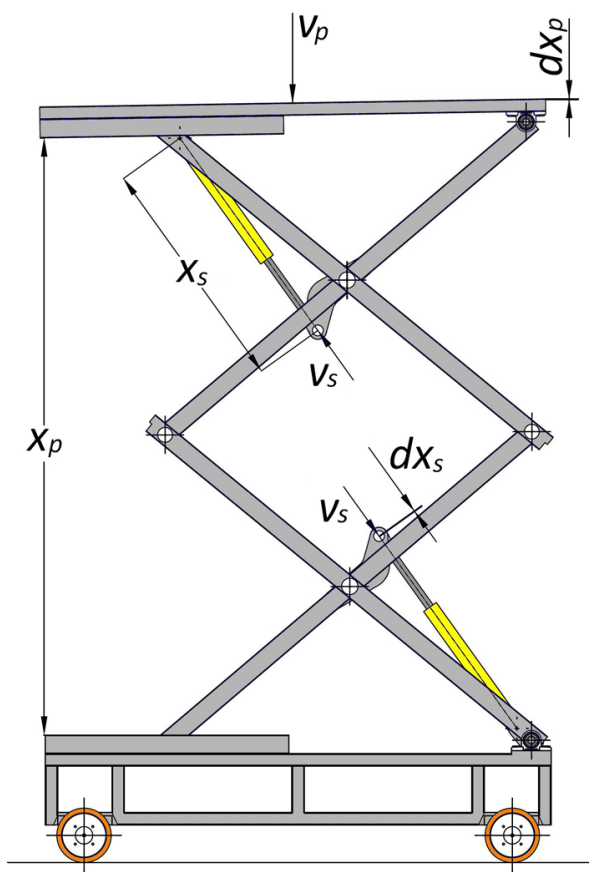

Fig. 3. Scissor lift

Fig. 3 presents a schematic drawing of the discussed scissor lift. The height of the platform $x_{p}$ is determined from the length of the hydraulic cylinder $x_{s}$. The nonlinear dependence between the displacement of the hydraulic cylinder and the platform indicates the variable mechanism ratio $i$, calculated according to Eq. (3), where $v_{p}$ and $v_{s}$ are the platform and hydraulic cylinder speeds, respectively.

$$
i=\frac{v_{p}}{v_{s}}=\frac{d x_{p}}{d x_{s}} .
$$

Furthermore, the lower the platform position, the higher pressure in the system. In commonly used 
systems, the platform speed increases inversely with the height of the platform. It is related to the use of throttle valves to control the lowering payload. It should be emphasized that during lowering the payload, the electric motor may be off or if it operates, the pump may force oil to the tank, for example, according to the right position of the directional valve 5 shown in Fig. 1. However, the dependence of the speed on the load in the classical system has an impact on the energy consumption. The lowering phase time increases with the decreasing load, and thus the supply time of the directional valve coil increases.

The pump flow rate $Q_{p}$, according to the Eq. (4), depends on parameters of the pump, such as volumetric efficiency $\eta_{v p}$ and displacement $q_{p}$ and angular speed of the pump shaft $\omega_{m}$.

$$
Q_{p}=\frac{q_{p} \cdot \omega_{m}}{\eta_{v p}} .
$$

The consequence is maintaining the hydraulic cylinder speed $v_{s}$ proportional to the oil flow rate $Q_{p}$, and inversely proportional to the cross-sectional area of the piston $A_{s}$, according to Eq. (5).

$$
v_{s}=\frac{Q_{p}}{A_{s}} .
$$

The use of a drive with a motor fed by FI enables the full control of the speed of lowering the platform, regardless of the load. To obtain the assumed speed of the electric motor, FI is used. Nowadays, most FIs are equipped with a vector control mode (VFD), also called field-oriented control (FOC), which keeps a stable motor speed regardless of its load. FOC mode ensures work safety and the ability to work at low speeds, for example, during precise load positioning. Moreover, this mode allows stopping a hanging load at any height without using an electro-mechanical motor brake and resuming the movement at any time. The correctness of speed mapping is very high (up to $0.01 \%$ ). Therefore, the presented studies are carried out using an electric motor fed by the FI operating in FOC mode.

\section{SOLUTION CONCEPT}

The main features of the new control system, in addition to changing the control method from throttling to volumetric, are the simplicity and the possibility of using it in a typical hydraulic system, equipped with a fixed displacement pump, an asynchronous electric motor, and hydraulic valves. The elements of the new system (Fig. 4) are as follows:

- electric motor fed by FI operating in FOC mode;
- reversible gear pump;

- $\quad$ solenoid operated check valve 2/2 (SOCV);

- open-loop controller (OLC);

- the hydraulic cylinder position sensor (in the case of variable-ratio mechanism).

The use of the SOCV allows both lifting and lowering of the hydraulic cylinder. During a power failure, the valve is closed and prevents the cylinder from falling. Lowering is carried out by sending a piloted signal to the coil of this valve simultaneously with the FI input signal, proportional to the assumed speed. The oil flows from the hydraulic cylinder through the valve to the hydraulic reversible pump, which operates as a hydraulic motor. The electric motor is driven by the pump and acts as a generator. The assumed speed of the electric motor (and pump) is maintained using the FI. The appropriate torque on the pump shaft is the result of the FI control system operation.

The controller allows declaring any voltage function that will be sent to the FI. This can be useful during automation, as well as to reduce overloads and ensures the safety of people or goods, which can increase the lifetime of the system.

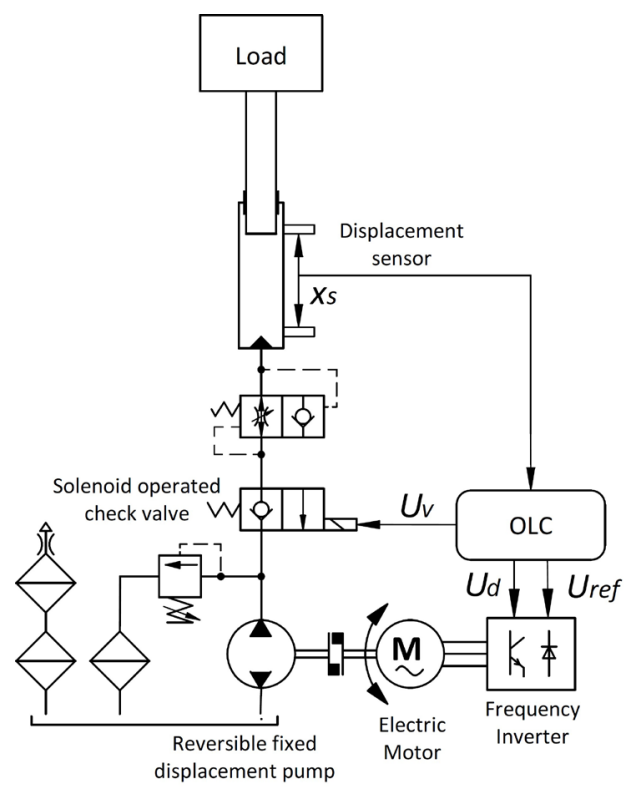

Fig. 4. The hydraulic and control system

The use of a position sensor located on the hydraulic cylinder is necessary only when the system drives the mechanism with a variable ratio, and the working element is controlled (in the presented case: the platform). Based on the position sensor mounted on the hydraulic cylinder and the known, determined because of geometric data, variable ratio, it is possible 
to control the speed of any selected element of the structure (e.g. scissor lift platform). The principle of operation of the control system is presented in Fig. 5. In the OLC algorithm, the current position of the hydraulic cylinder $x_{s}$ allows determining momentary mechanism ratio $i$, which is calculated as a polynomial function, presented in Eq. (6).

$$
i=\sum_{i=0}^{n} a_{i} \cdot x_{s}^{i}
$$

The displacement of the working element with assumed speed $v_{\text {Aset }}$ is realized by forcing the appropriate speed $\omega_{m s e t}$ of the electric motor according to Eq. (7).

$$
\omega_{\text {mset }}=v_{\text {Aset }} \cdot \frac{A_{s}}{q_{p}} .
$$

The reference signal from the OLC to the FI $U_{\text {ref }}$ is proportional to the motor speed and is defined by Eq. (8), where $k_{\omega}$ is the conversion coefficient, and $i_{\min }$ is the minimum value of the mechanism ratio:

$$
U_{\text {ref }}=\frac{\omega_{m s e t}}{i} \cdot i_{\min } \cdot k_{\omega}
$$

In the case of lowering the payload, the controller simultaneously sends binary signals to the solenoidoperated check valve $2 / 2$ (opening the flow from the cylinder to pump) and FI (reverse direction of the motor rotation). The oil begins to flow from the hydraulic cylinder to a pump that works like a hydraulic motor.

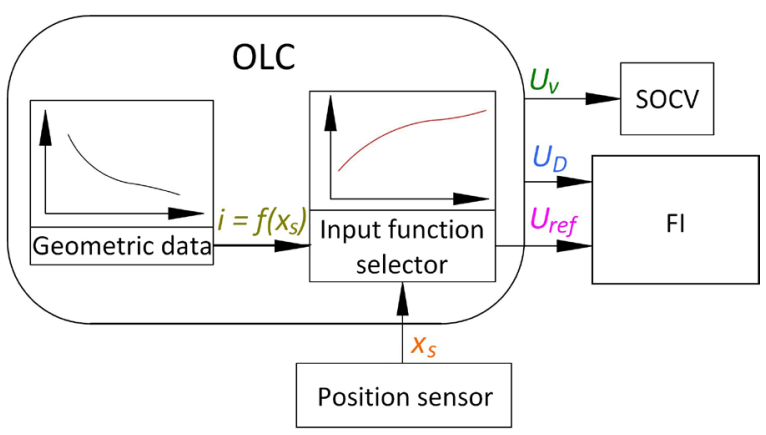

Fig. 5. Open-loop controller (OLC)

\section{TEST STAND}

Experimental tests were carried out on a customdesigned scissor lift prototype (Fig. 6).

The stand was equipped with the drive components and the proposed speed control system shown in Table 1. For the determination of the mechanism ratio, a position sensor of the hydraulic cylinder piston rod is installed. Additionally, a platform position sensor is used to verify the movement of the actuator element and the power network analyser is used to measure the power consumption of the drive system. The OLC has been designed using the LabVIEW software installed on a PC co-operating with a multifunction input/output (I/O) device.

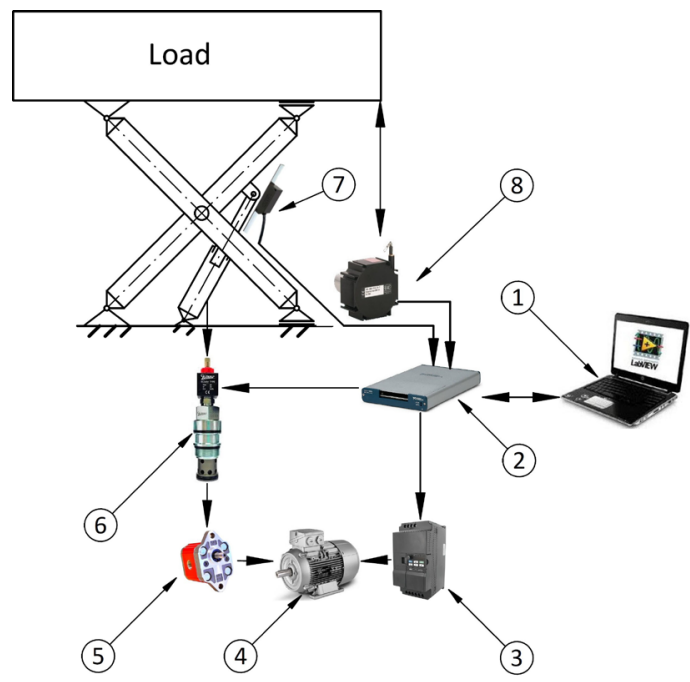

Fig. 6. Scissor lift test stand

The principle of operation of the controller is based on the equations described above. The mechanism ratio $i$ as a function of the hydraulic cylinder displacement $x_{s}$, shown in Fig. 7, was

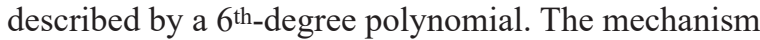
ratio changes from 13 in the lower platform position to 6.6 in its upper position.

Table 1. Test stand setup

\begin{tabular}{cll}
\hline No. & Component & Parameters \\
\hline 1 & PC + LabVIEW & Dell Inspiron 17 G3 3779 \\
2 & Software NI USB 6434 & 16 Al, 2 A0, 24 DIO USB \\
\hline \multirow{2}{*}{3} & Frequency Inverter SX2400- & $0.75 \mathrm{~kW} /$ \\
& OR7G-2 & $0 \mathrm{~V}$ to 10 V \\
\hline 4 & Motor Simotics GP 1AV1082B & $0.55 \mathrm{~kW} / 1385 \mathrm{rpm}$ \\
\hline 5 & Pump XV-0R/0.98 & $0.92 \mathrm{~cm} 3 / \mathrm{rev}$ \\
\hline \multirow{2}{*}{6} & Solenoid-operated check valve 2/2 & $350 \mathrm{bar} /$ \\
& EP-08W-05-M-04 & $30 \mathrm{l} / \mathrm{min}$ \\
\hline \multirow{2}{*}{7} & Hydraulic cylinder position sensor & $1.5 \mathrm{~m} /$ \\
& EMAX-000-01.5-2-CA0 & $125 \mathrm{kBit} / \mathrm{s}$ \\
\hline \multirow{2}{*}{8} & Platform position sensor WDS- & $3000 \mathrm{~mm} /$ \\
& 3000-P96-CR-TTL & $11.53 \mathrm{pulses} / \mathrm{mm}$ \\
\hline & &
\end{tabular}

The presented mechanism is the only case that requires an additional sensor. This is due to the variable ratio of the mechanism and the necessity of determining the ratio to maintain the assumed speed of the platform. This entails the need to know the 
geometry of the mechanism and its ratio. Constant ratio mechanisms do not require a sensor of cylinder displacement.

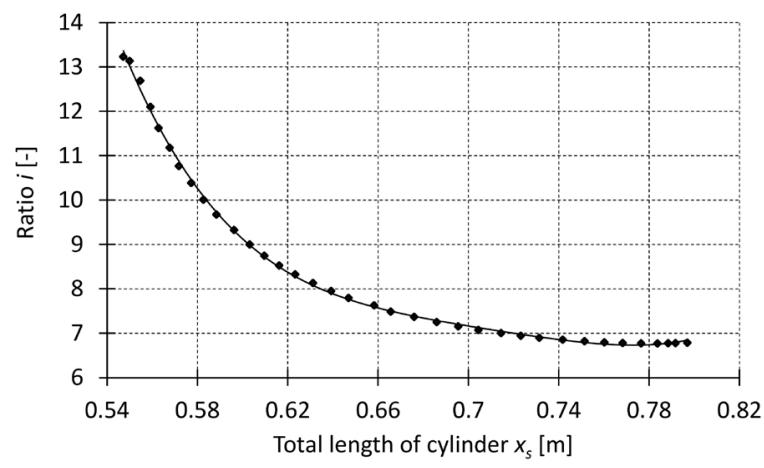

Fig. 7. Mechanism ratio $i$ as a function of the hydraulic cylinder displacement $x_{S}$

\section{EXPERIMENTAL INVESTIGATION AND RESULTS}

The experimental tests were divided into two sections:

1. Comparison of the assumed speeds with measured on the stand.

2. Testing the influence of the load on maintaining the assumed speeds.

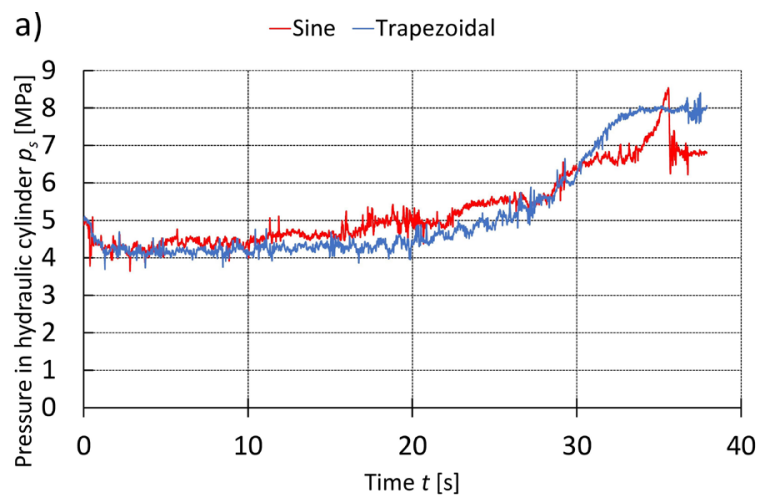

b)

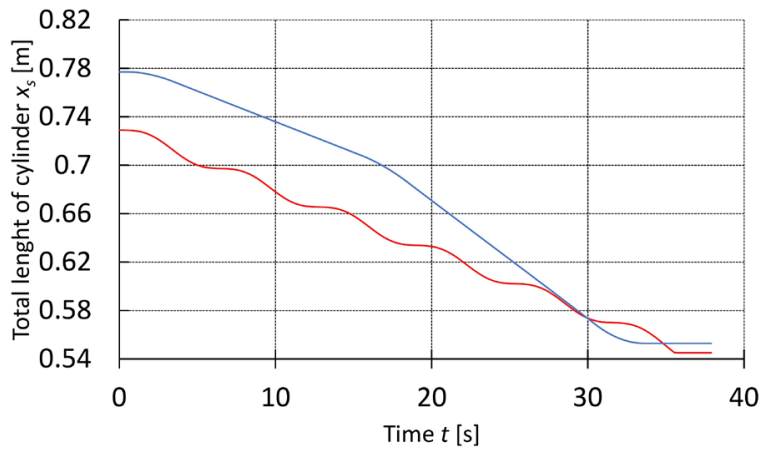

Fig. 8. Comparison of a) sine and trapezoidal functions for pressure in the hydraulic cylinder, and b) total hydraulic cylinder length during the lowering cycle
Each section was tested separately for the assumed speed of the hydraulic cylinder and the actuator - a scissor lift platform.

\subsection{Verification of the OLC}

The scissor lift loaded with a nominal load of $96 \mathrm{~kg}$ (100\% load) was used for the tests. The platform was lowered using two control functions: sine and trapezoidal. These functions are the base for further studies related to the minimization of dynamic loads, in which both types of inputs will be used. Fig. 8a presents the pressure change $p_{s}$ in hydraulic cylinders during the lowering. It is a visible change of the pressure from $4.5 \mathrm{MPa}$ at the start (upper) position to almost $7 \mathrm{MPa}$ (sine) and $8 \mathrm{MPa}$ (trapezoidal) at the end cycle when the platform is at the bottom position. Fig. $8 \mathrm{~b}$ presents the actual length of the hydraulic cylinder $x_{s}$.
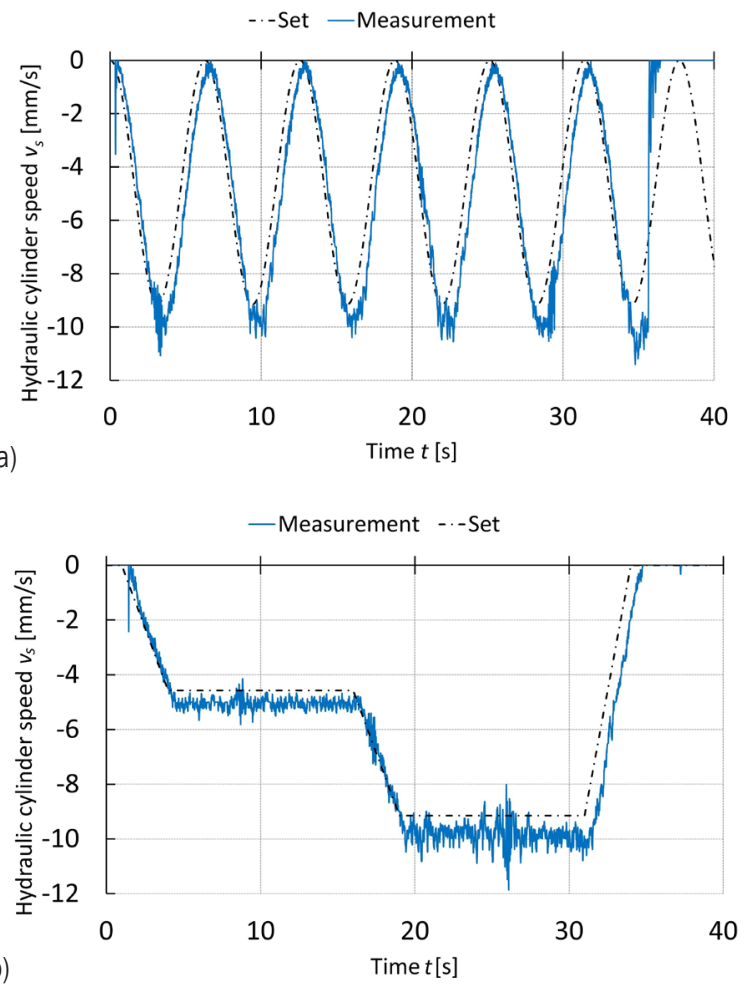

Fig. 9. Comparison of the set and measured speeds of the hydraulic cylinder $\left(v_{s}\right)$; a) sine, and b) trapezoidal

The waveforms presented in Fig. 9 show the speed of the hydraulic cylinder with a) sine, and b) trapezoidal control functions. In both cases, the difference between the speeds increases with time. This is due to the diminishing volumetric efficiency of the pump due to the increasing leaks under pressure 
growth in the hydraulic system during lowering. The maximum difference between the set speed and the actual speed is $2.4 \mathrm{~mm} / \mathrm{s}$.

The OLC allows continuous adjustment of the speed of the hydraulic cylinder and thus the scissor lift platform. The assumed and measured waveforms of the platform speed are presented, respectively, in Fig. 10. As with the hydraulic cylinder, the platform speed increases when the platform is lowered. The proposed control system does not consider the change of efficiency of the pump. This is a field for further research and development of the possibilities of the presented method of speed regulation. However, in this case, the maximum difference between the set speed and the actual speed is $5.9 \mathrm{~mm} / \mathrm{s}$.

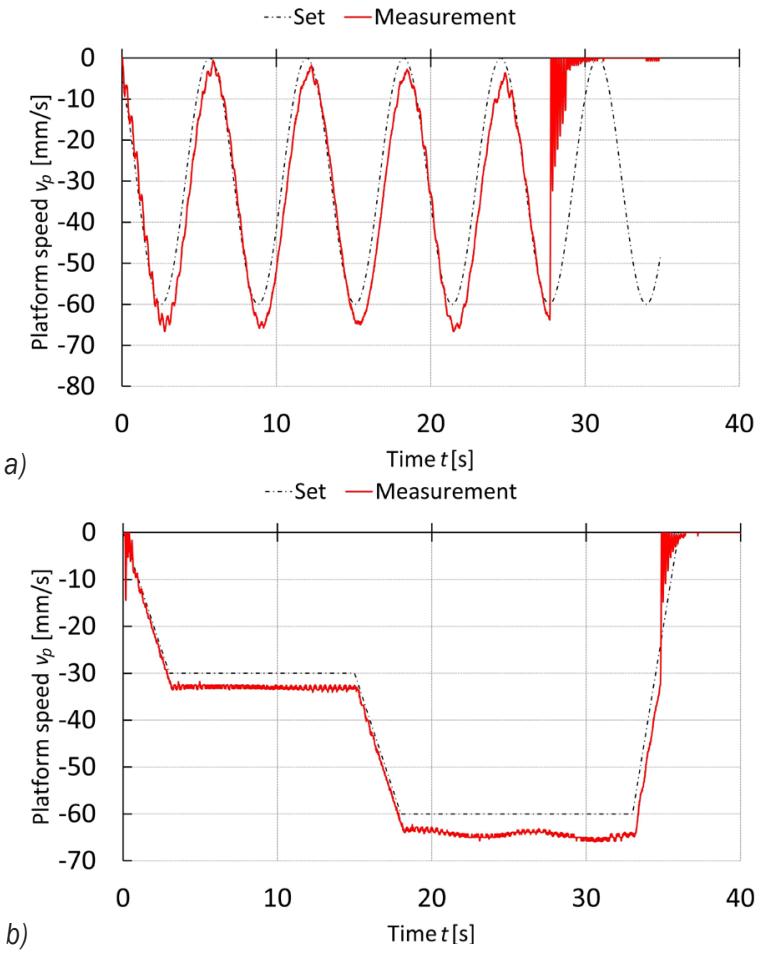

Fig. 10. Comparison of the set and measured speeds of the scissor lift platform ( $\left.v_{p}\right)$; a) sine, and b) trapezoidal

\subsection{Load Impact on the OLC}

The objective of the second section of the experiments is to validate the proposed control structure for different test cases covering the operating range of the drive. Operation of the system is evaluated with an external load at the level of $(0,50,100) \%$ of the nominal load (respectively, $0 \mathrm{~kg}, 48 \mathrm{~kg}$ and $92 \mathrm{~kg}$ ) for lowering the platform from a height of $2150 \mathrm{~mm}$. The voltage reference functions are carried out in the following cases:
- $U_{\text {ref }}$ as a function proportional to the assumed speed of the hydraulic cylinder $v_{s}=-9.15 \mathrm{~mm} / \mathrm{s}$ with smooth acceleration and deceleration 1-second ramp (Fig. 11).

- $U_{\text {ref }}$ as a function proportional to the assumed speed of the platform $v_{p}=60 \mathrm{~mm} / \mathrm{s}$ with smooth acceleration and deceleration 1-second ramp (Fig. 12).

To facilitate the reading of Figs. 11 to 13, the magnifications of the selected areas of the charts are placed.

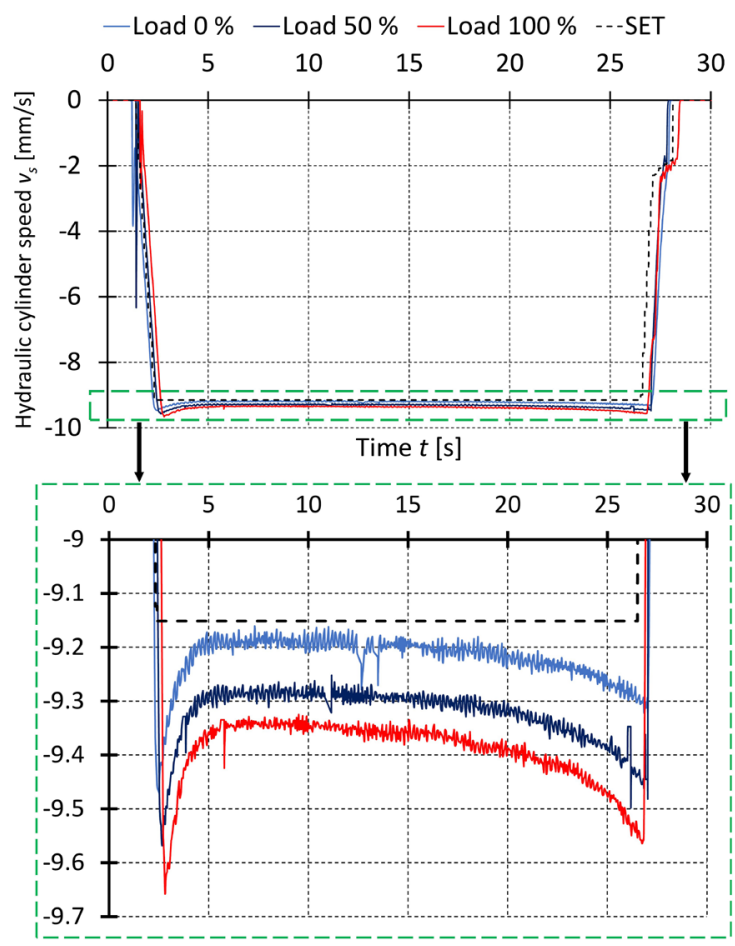

Fig. 11. Comparison of the set and measured speeds $v_{S}$ of the hydraulic cylinder with different loads

The applied ramps reduced the overloads and vibrations emerging in the system. This increases the service life of the entire machine and affects the safety of the transported cargo or the comfort of people.

Both the speed of the hydraulic cylinder and the platform maintain the assumed speeds regardless of the load. The maximum difference between the set platform speed is $10 \%$ and the average is $6 \%$. Detailed differences are presented in Table 2, where set is reference value of the platform speed, maximal actual value of the platform speed, and mean arithmetical mean of the actual platform speed during steady motion. 


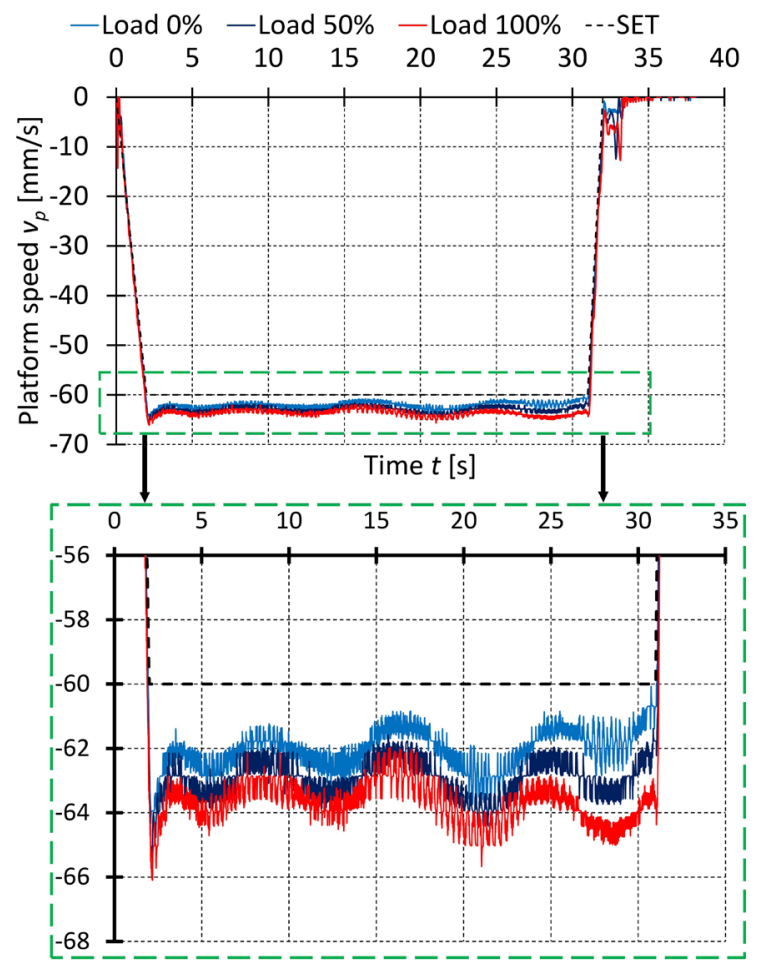

Fig. 12. Comparison of the set and measured speeds $v_{p}$ of the scissor lift platform with different loads
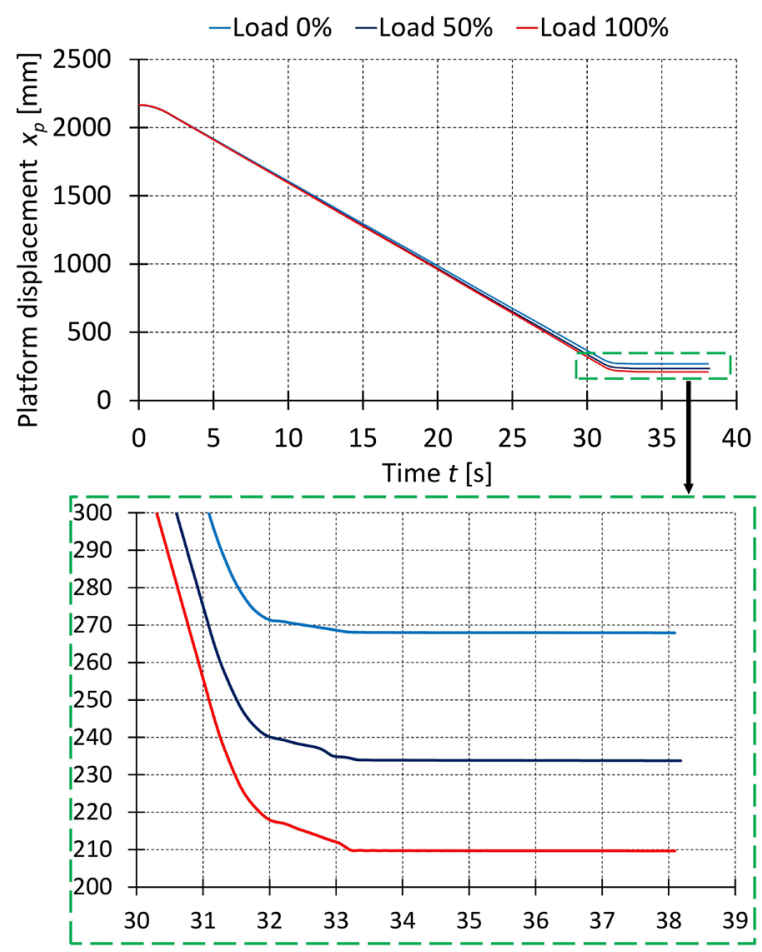

Fig. 13. Platform displacement $x_{p}$ with different loads
The difference in the position of the platform after lowering it over the same period is $58 \mathrm{~mm}$ between a fully loaded and empty lift. The displacements of lowering the platform for different loads are shown in Fig. 13.

These values result from a decline in the volumetric efficiency of the pump with increasing pressure. To eliminate these differences, a pump leakage compensation system or close loop control system should be used. During the tests, the electrical parameters in the line supplying of the stand were also recorded. Measurement of instantaneous power allowed to determine the energy consumed in each cycle. A conventional drive system and a new one were used for comparison.

Table 2. Comparison of platform speed $v_{p}$ for different loads

\begin{tabular}{cccc}
\hline Load & \multicolumn{3}{c}{ Platform speed } \\
\cline { 2 - 4 }$[\%]$ & set $v_{p}[\mathrm{~mm} / \mathrm{s}]$ & $\max v_{p}[\mathrm{~mm} / \mathrm{s}]$ & mean $v_{p}[\mathrm{~mm} / \mathrm{s}]$ \\
\hline 0 & -60 & -64.33 & -62.05 \\
\hline 50 & -60 & -65.73 & -62.93 \\
\hline 100 & -60 & -66.10 & -63.70 \\
\hline
\end{tabular}

Fig. 14 presents the comparison of power consumption during the lowering cycle. To illustrate the cycle, the platform displacement is presented as well. The actual power consumption of the conventional drive is at the constant level during the whole cycle, what is visible in Fig. 14a. It results from the constant power demand of the device control system and the supply of the throttle valve coil. One of the disadvantages of this system is the dependence of the load on the lowering time, which can reach over $120 \mathrm{~s}$ for an empty platform. The new setup of the valve can change these cycle times. Fig. 14b shows that the power consumption depends on the platform displacement, but all cycles are about $35 \mathrm{~s}$. The duration of the cycle depends only on the settings of its parameters, such as the assumed speed or the times of the individual cycle phases. The FI installed on the stand cannot return energy into the power network. To estimate the energy balance of a drive capable of returning energy to the power network, based on the measured hydraulic quantities associated with the pump, the power recoverable $P_{m}$ during lowering was determined according to dependency:

$$
P_{m}=q_{p} \cdot \omega_{m} \cdot p_{p} \cdot \eta_{m} \cdot \eta_{p},
$$

where $q_{p}$ is pump displacement, $\omega_{m}$ actual angular speed of the pump shaft, $p_{p}$ actual pressure on the pump outlet, $\eta_{p}$ pump efficiency, and $\eta_{m}$ electric motor efficiency. 

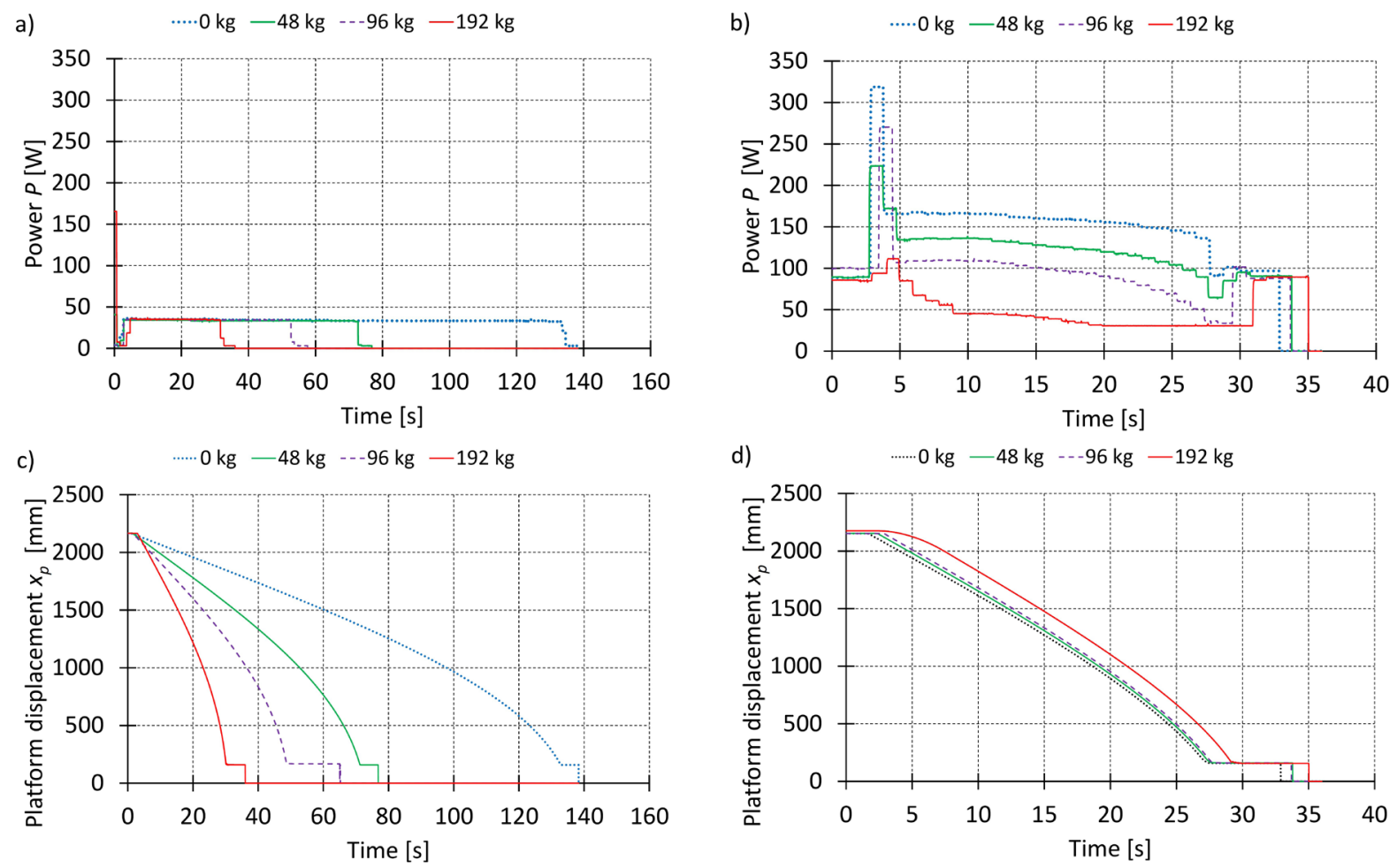

Fig. 14. Power consumption $P$ and platform displacement $x_{p}$ during lowering cycle: a), c) conventional, b), d) new

To estimate the energy consumption $E$, the power function was integrated according to the Eq. (10):

$$
E=\int_{0}^{t}\left(P-P_{m}\right) d t
$$

Fig. 15 presents the comparison of the lowering energy of the three systems:

- conventional with directional and throttle valves,

- new with FI,

- new with FI and energy recuperation estimation.

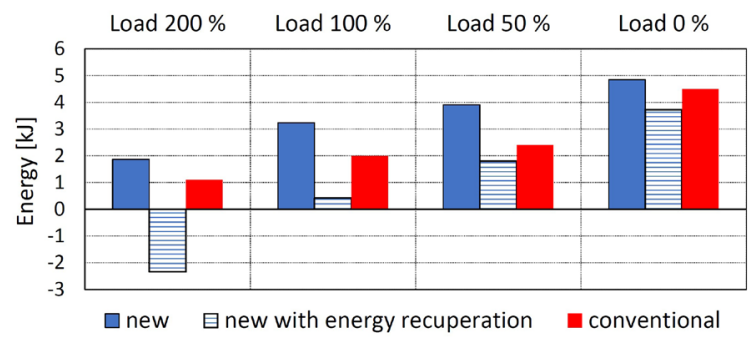

Fig. 15. Lowering energy comparison with different platform loads and drive systems

It is visible that the ability to free mapping of the speed using the new system costs a certain amount of energy. Differences reached even about $60 \%$ for the system without energy recuperation. It should be noted that this is a low-capacity drive and the difference in energy demand decreases with increasing load.

When this feature is included, the system gives lower energy consumption for the empty platform and small loads (from $20 \%$ to $87 \%$ ) and energy recuperation in case of maximum load. The reduction in power consumption results from the fact that the motor working during lowering as a generator, transfers electric power to the DC link of FI, which in common FI's is lost to the resistor. The FI's equipped with the regenerative unit allows energy to return to the grid when the DC link voltage level is too high. It causes a real decrease in energy demand, e.g., in lowering cycles.

\section{CONCLUSIONS}

The proposed system of controlling the lowering of the hydraulic cylinder maintains the set speed with high accuracy. The used method of control simplifies the structure of the hydraulic system, among others the throttle valve and directional valve are removed. New drive allows freely shaping of the speed of the piston rod or working element (e.g. platform) depending on the needs. However, it causes the increased energy 
consumption in relation to the classical system. The presented system can be, although energy efficient by using FI equipped with a regenerative unit, despite that the scissor lift is a relatively low-capacity machine.

This system has significant advantages over other methods of speed control and positioning for lowering payload. These are, among others: simple structure, low price, the possibility of using any size, and type of pump. This means that the presented solution of the volumetric control of hydrostatic drives can be used without any limitation of a pump size in contrary to variable displacement pumps, which are produced in sizes above $8 \mathrm{~cm}^{3} / \mathrm{rev}$. This extends the possibility of volumetric control also to low power driving systems.

Additionally, the possibility of continuous adjustment of the pump motor speed allows minimizing adverse phenomena occurring during acceleration, such as vibrations or overloads.

The presented solution significantly extends the possibilities of controlling hydraulic systems in both passive and active loads.

\section{NOMENCLATURES}

$A_{D}$ cross-sectional area of valve orifice, $\left[\mathrm{m}^{2}\right]$

$A_{s}$ cross-sectional area of piston, $\left[\mathrm{m}^{2}\right]$

$c_{D} \quad$ coefficient of flow losses, [-]

$d s$ diameter of hydraulic cylinder, [m]

$E$ energy consumption, [J]

$i$ mechanism ratio, [-]

$k_{\omega} \quad$ conversion coefficient, $[\mathrm{V} \cdot \mathrm{s} / \mathrm{rad}]$

$P_{m}$ recoverable power, [W]

$p_{p} \quad$ actual pressure on pump outlet, [MPa]

$\Delta p_{s}$ pressure drop between valve inlet and outlet, [MPa]

$q_{p} \quad$ pump displacement, [ $\left.\mathrm{m}^{3} / \mathrm{rev}\right]$

$Q_{D}$ throttling valve flow rate, $\left[\mathrm{m}^{3} / \mathrm{s}\right]$,

$Q_{p}$ pump flow rate, $\left[\mathrm{m}^{3} / \mathrm{s}\right]$,

$U_{\text {ref }}$ reference signal from OLC, [V]

$v_{\text {Aset }}$ assumed speed of working element, $[\mathrm{m} / \mathrm{s}]$

$v_{p}$ and $v_{s}$ are the platform speed, $[\mathrm{m} / \mathrm{s}]$

$v_{s}$ hydraulic cylinder speed, $[\mathrm{m} / \mathrm{s}]$

$x_{p}$ height of platform, [m]

$x_{s} \quad$ length of hydraulic cylinder, $[\mathrm{m}]$

$\eta_{m}$ electric motor efficiency, [-]

$\eta_{p} \quad$ pump efficiency, [-]

$\eta_{v p}$ pump volumetric efficiency, [-]

$\rho$ density of hydraulic liquid, $\left[\mathrm{kg} / \mathrm{m}^{3}\right]$

$\omega_{m}$ actual angular speed of pump shaft, $[\mathrm{rad} / \mathrm{s}]$

$\omega_{m s e t}$ assumed speed of electric motor, [rad/s].

\section{REFERENCES}

[1] Liu, Y.; Li, W., Li, D. (2018). Review on inlet/outlet oil coordinated control for electro-hydraulic power mechanism under sustained negative load. Applied Sciences, vol. 8, no. 6: art. ID 886, D0I:10.3390/app8060886.

[2] Bednarski, S. (2012). Controlled movement of the hydraulic cylinder with active load. Hydraulika I Pneumatyka, no. 2, p. 10-14. (in Polish)

[3] Stawiński, Ł. (2011) Hydrostatic systems for driving cylinders with variable direction loading of the piston rod. Hydraulika $i$ Pneumatyka, no. 1, 17-20. (in Polish)

[4] Dabholkar, R., Indulkar, S. (2012). Overcenter valves are key to hydraulic control. Design World, from https://www. designworldonline.com/overcenter-valves-are-key-tohydraulic-control/, accessed on 2020-11-23.

[5] Hitchcox, A. (2009). The Truth about Problem Valves, Hydraulics \& Pneumatics. The Penton Media Buildings, Cleveland.

[6] Johnson, J.L., (2009). Counterbalance Valve Circuits, Hydraulics \& Pneumatics, The Penton Media Building, Cleveland.

[7] Zähe, B. (2010). Für einen besseren Wirkungsgrad. Auswahl und Verschaltung von Senkbremsventilen. SUN Hydraulik $\mathrm{GmbH}$ in Erkelenz, Mainz.

[8] Nordhammer, P.A., Bak, M.K., Hansen, M.R. (2012). A method for reliable motion control of pressure compensated hydraulic actuation with counterbalance valve. Proceedings of the $12^{\text {th }}$ International Conference on Control. Automation and Systems, p. 759-763.

[9] Nordhammer, P.A., Bak, M.K., Hansen, M.R. (2012). Controlling the slewing motion of hydraulically actuated crane using sequential activation of counterbalance valve. Proceedings of the $12^{\text {th }}$ International Conference on Control. Automation and Systems, p. 773-778.

[10] Dasgupta, K., Watton, J. (2018). Modeling and dynamics of a two-stage pressure rate controllable relief valve: A bondgraph approach. International Journal of Modelling and Simulation, vol. 28, no. 1, p. 11-19, D0l:10.1080/02286203.2008.11442 444.

[11] Stawiński, Ł. (2016). Experimental and modeling studies of hydrostatic systems with the counterbalance valves which are used in hydraulic lifting systems with passive and active load. Eksploatacja i Niezawodnosc - Maintenance and Reliability, vol. 18, no. 3, p. 406-412, Dol:10.17531/ein.2016.3.12.

[12] Zhao, L., Xinhui, L., Tongjian, W. (2010). Influence of counterbalance valve parameters on stability of the crane lifting system. Proceedings of the International Conference on Mechatronics and Automation, p. 1010-1014, D0l:10.1109/ icma.2010.5589356.

[13] Agostini, T., De Negri, V., Minav, T., Pietola, M. (2020). Effect of energy recovery on efficiency in electro-hydrostatic closed system for differential actuator. Actuators, vol. 12, Iss. 9, art. ID 12, D0I:10.3390/act9010012.

[14] Cochran, K. (2012). Cartridge valve and manifold technologies - a component approach to improved energy efficiency. Proceedings of the Energy Efficient Hydraulics and Pneumatics Conference, Rosemont. 
[15] Andersen, B.R. (2009). Energy efficient load holding valve. Proceedings of the $11^{\text {th }}$ Scandinavian International Conference on Fluid Power, Linkoping.

[16] Bao, Z. (2019). Study on simulation of system dynamic characteristics of hydraulic scissor lift based on loadsensing control technology. IOP Conference Series: Materials Science and Engineering, vol. 612, no. 4, art. ID 042036, DOl:10.1088/1757-899X/612/4/042036.

[17] Heikkila, M., Linjama, M. (2013). Displacement control of a mobile crane using a digital hydraulic power management system. Mechatronics, vol. 23, no. 4, p. 452-461, DOI:10.1016/j.mechatronics.2013.03.009.

[18] Lyu, L., Chen, Z., Yao, B. (2018). High precision and high efficiency control of pump and valves combined hydraulic system. Proceedings of the $15^{\text {th }}$ International Workshop on Advanced Motion Control (AMC), p. 391-396, D0l:10.1109/ AMC.2019.8371124.

[19] Minav, T., Immonen, P., Laurila, L., Vtorov, V., Pyrhonen, J., Niemela, M. (2011). Electric energy recovery system for a hydraulic forklift - theoretical and experimental evaluation. IET Electric Power Application, vol. 5, no. 4, p. 377-385, D0I:10.1049/iet-epa.2009.0302.

[20] Lovrec, D., Tic, V., Tasner, T. (2017). Dynamic behaviour of different hydraulic drive concepts - comparison and limits. International Journal of Simulation Modelling, vol. 16, no. 3, p. 448-457, D0l:10.2507/ijsimm16(3)7.389.

[21] Avram, M., Spânu, A., Sârbu, V. (2018). Method for controlling the hydraulic pump flow following an imposed frequency law for AC motors. IOP Conference Series: Materials Science and Engineering, vol. 444, no. 4, art. ID 042009, DOI:10.1088/1757-899X/444/4/042009.

[22] Kosucki, A., Stawiński, Ł. (2016). Studies on hydrostatic systems powered by frequency inverters. Proceedings of the
International Scientific and Technical Conference: Hydraulic and Pneumatic Drives and Control, vol. 1, p. 5-16. (in Polish)

[23] Yang, X., Gong, G., Yang, H., Jia, L., Zhou, J. (2017). An investigation in performance of a variable-speed-displacement pump-controlled motor system. IEEE/ASME Transactions on Mechatronics, vol. 22, no. 2, p. 647-656, D0l:10.1109/ tmech.2016.2544440.

[24] Padovani, D., Ketelsen, S., Hagen, D., Schmidt, L. (2019). A self-contained electro-hydraulic cylinder with passive loadholding capability. Energies, vol. 292, no. 12, art. ID 292, DOl:10.3390/en12020292.

[25] Ritelli, G.F., Vacca, A. (2013). Energetic and dynamic impact of counterbalance valve in fluid power machines. Energy Conversion and Management, vol. 76, p. 701-711, D0l:10.1016/J.enconman.2013.08.021.

[26] Stawiński, Ł., Kosucki, A., Morawiec, A., Sikora, M. (2019). A new approach for control the velocity of the hydrostatic system for scissor lift with fixed displacement pump. Archives of Civil and Mechanical Engineering, vol. 19, no. 4, p. 1104-1115, D0l:10.1016/j.acme.2019.06.001.

[27] Stawinski, Ł., Zaczynski, J., Morawiec, A., Skowronska, J., Kosucki, A. (2021). Energy consumption structure and its improvement of low-lifting capacity scissor lift. Energies, vol. 14, no. 5, art. ID 1366, D0I:10.3390/en14051366.

[28] Stancek, J., Bulej, V. (2015). Design of driving system for scissor lifting mechanism. Academic Journal of Manufacturing Engineering, vol. 13, no. 4, p. 38-43.

[29] Hongyu, T., Ziyi, Z. (2011). Design and simulation based on Pro/E for a hydraulic lift platform in scissors type. Procedia Engineering, vol, 16, p. 772-781, D0I:10.1016/j. proeng.2011.08.1153.

[30] Liu, T., Jian, S. (2009). Simulative calculation and optimal design of scissor lifting mechanism. Proceedings of the Chinese Control and Decision Conference, p. 2079-2082. 